\title{
Hazard analysis and consequences assessment of gas pipeline rupture and natural gas explosion
}

\author{
E. Uspuras, S. Rimkevicius, M. Povilaitis, \\ T. Iesmantas \& R. Alzbutas \\ Lithuanian Energy Institute, Lithuania
}

\begin{abstract}
Natural gas is commonly used as a fuel. Large distances between natural gas supply sources and consumers has led to extensive networks of natural gas pipelines. Since natural gas is a flammable and explosive fuel, it is hazardous and its transportation has inherent risks associated with potential damage. Accidental gas pipeline explosions could lead to extreme destruction and negative consequences. In order to estimate and reduce probability and potential damage of such explosions the good understanding of involved phenomena and ability to simulate them are needed. This paper presents hazard analysis and consequences assessment of gas pipeline rupture and natural gas explosion. Various mathematical models are described in the methodological part of the work. They help to figure out the hazard of the gas pipeline rupture and assess the size of risky zone reflecting the place of potential disaster. Also the probability of the gas explosion in relation to the particular gas pipeline is being estimated. Consequences are assessed considering possible combustion of natural gas which is released from the ruptured pipe. A point source model is used to describe the radiation intensity of flame thermal energy. Also, strength of hypothetical detonation is estimated using a TNT (Trinitrotoluene) equivalence method, by employing which equivalent TNT charge is estimated from the energy released in the gas explosion. According to obtained intensities a distance and period of time related to various injuries to people and damage to buildings are estimated.

Keywords: natural gas, hazard analysis, pipeline rupture, explosion, point source model, TNT equivalence method.
\end{abstract}




\section{Introduction}

Natural gas is a commonly used energy source. Due to different geographical distributions of natural gas supply sources and consumers, large distances have to be covered by extensive networks of pipelines delivering natural gas. Since natural gas is a flammable and explosive fuel, it is hazardous and its transportation has inherent risks associated with potential damage. Accidental gas pipeline explosions could lead to extreme destruction and negative consequences.

In order to estimate and reduce probability and potential damage of natural gas pipelines explosions the good understanding of involved phenomena and ability to simulate them are needed. This paper presents hazard analysis and consequences assessment of gas pipeline rupture and hypothetical natural gas explosion. Various mathematical models are described in the methodological part of the work. They help to figure out the hazard of the gas pipeline rupture and assess the size of risky zone reflecting the place of potential disaster. Also the probability of the gas explosion in relation to the particular gas pipeline is being estimated.

Consequences of the natural gas pipeline accident are assessed in the paper considering possible combustion of natural gas which is released from the ruptured pipe. A point source model is used to describe the radiation intensity of flame thermal energy. According to obtained intensities a distance and period of time related to various injuries to people and damage to buildings are estimated. Also strength of hypothetical detonation is estimated using a TNT (Trinitrotoluene) equivalence method, by employing which equivalent TNT charge is estimated from the energy released in the gas explosion.

\section{Probabilistic analysis}

Uncontrolled release of natural gas or loss of pressure in the system may cause unsafe situations due to the potentially explosive mixture of gas and air [1]. Usual practice in assessment of such hazardous events is to consider failures rate of gas pipelines as constant value rate. In such a case the probability of gas explosion per year is also estimated as constant:

$$
P=\lambda \cdot D \cdot f_{s} \cdot f_{t} \cdot f_{d} \cdot f_{w}
$$

where $\lambda$ is frequency of $1 \mathrm{~km}$ pipeline failure per year, $D$ is pipeline length $(\mathrm{km})$, close to considered object, $f_{s}$ is hazardous pipeline accidents frequency, $f_{t}$ frequency of accidents related to technical works performed close to site, $f_{d}$ unnoticed and unrepaired accidents, $f_{w}$ - ratio of adverse weather conditions.

Conservative estimates of parameters for the equation (1) are available in various sources (e.g. [2] or [3]) and for this analysis were assumed as presented in the following table. 
However, due to dynamic operating environment and other features the real failure rate is age-dependent. The historical failure data [3] may be used to model age-dependent reliability of pipelines in terms of Bayesian methods, which have advantages of being capable to manage scarcity and rareness of data and of being easily interpretable for engineers [4].

Table 1: $\quad$ Parameter values.

\begin{tabular}{|c|c|}
\hline Parameters & Value \\
\hline$D$ & $1(\mathrm{~km})$ \\
\hline$f_{s}$ & 0.32 \\
\hline$f_{t}$ & 0.25 \\
\hline$f_{d}$ & 0.1 \\
\hline$f_{w}$ & 0.5 \\
\hline
\end{tabular}

These results of age-dependent modelling and analysis of gas pipeline reliability are applied to estimate frequency of explosions due to natural gas release when pipeline failure occurs. Using equation (1) and developed relation for age-dependent failure rate

$$
\lambda(t)=0.11+\frac{0.52}{1+t}+0.26^{t}, 1 /(1000 \mathrm{~km} \cdot \text { year })
$$

the function of non-constant probability estimate of gas explosion can be presented like shown in Figure 1.

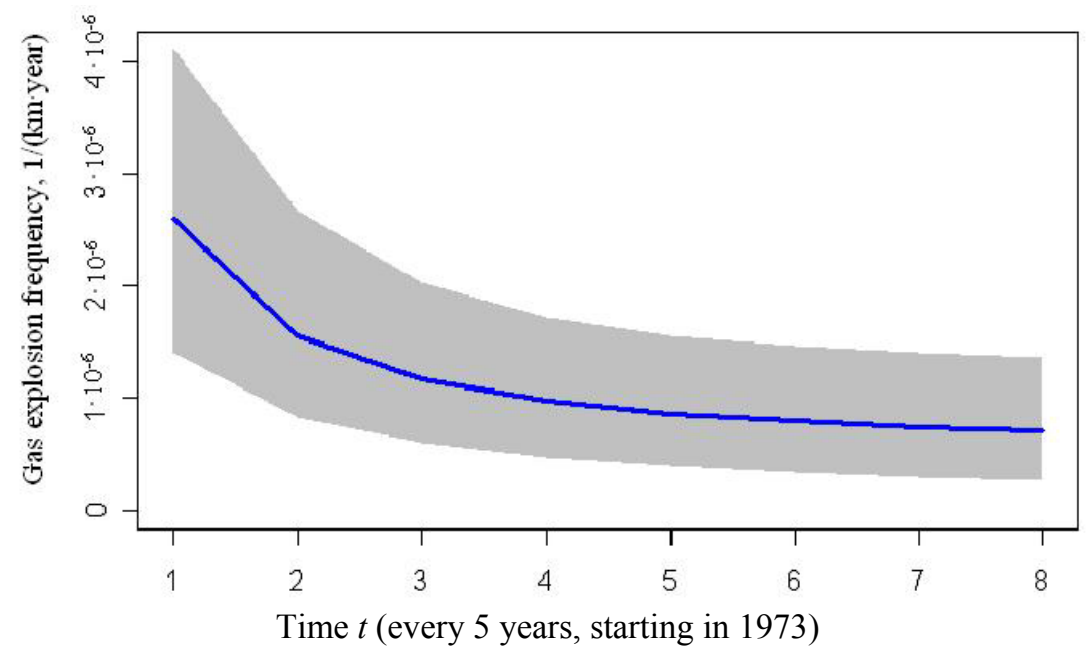

Figure 1: Estimate of age-dependent gas explosion probability and uncertainty.

The introduced age-dependent failure rate (2) is also useful for analysis of risk - this can be done by using the non-constant probability estimate of 
hazardous event and assessment of this event consequence. The estimation of age-dependant failure rate may reflect the uncertainty of statistical data and then it might be propagated to the estimate of explosion probability, as presented in Figure 1. The parameters important for assessment of explosion consequence (see the next section) are also uncertain and will be analysed in the future.

\section{Consequences assessment}

In this part of the paper pipeline rupture consequences related to the combustion of the released natural gas are assessed. Assessment method is based on the model developed by M. J. Stephens [5]. It is assumed in the model that combustion would occur in the form of the sustained jet fire. The heat flux radiated by this fire is estimated using a simple point-source model, described in the section 3.1. The obtained heat flux is used to assess the damage it could possibly cause, and the time needed to cause given damage (section 3.2). The section 3.3 presents an estimation of the shock wave, which could be caused by a hypothetical detonation of the released gas. The probability of such an event is extremely low in the case of methane gas, because of its buoyancy, unless obstacles for the gas dispersion were present. Because it is not possible to estimate the realistic volume of detonable mixture such obstacles would allow to form, an over-conservative amount is taken in our estimations. It is assumed to be equal to the whole gas contents of the affected pipeline section stoichiometrically mixed with the air.

\subsection{Radiation intensity of the flame}

In order to estimate a heat flux radiated by the combustion, a jet fire model is used. A jet flame is modelled as a point source of thermal radiation situated at the ground level. This simplifying approximation yields a lower accuracy than would a model of multiple point sources spread along the assumed length of the flame yield, however it greatly simplifies the calculations. Furthermore, result obtained with this approximation is conservative in relation to the damage receptor, which is at the low height compared to the real flame length. If a need arose to evaluate the radiation intensity in greater accuracy, it would be possible to disperse this single point source into the multiple point sources, and integrate their radiation received by the receptor (e.g., Carter jet flame model in [6]). However, in such a case more detailed analysis would be required to consider possible jet and receptor lengths and shapes.

The heat flux $I\left(\mathrm{~W} / \mathrm{m}^{2}\right)$ radiated by a point source at the distance $r(\mathrm{~m})$ from it is

$$
I(r)=F \tau \frac{Q}{4 \pi r^{2}}
$$

where $Q$ is the net heat release rate of the combustion (W), $\tau$ is the atmospheric transmissivity and $F$ is the fraction of the released heat which is radiated. The heat release rate itself is a product of the combustion rate of the fuel and the heat 
of combustion for the given fuel $H(\mathrm{~J} / \mathrm{kg})$. To simplify the model an assumption is made that, considering the gas pipelines, the combustion rate of the fuel is equal to the gas release rate from the pipe rupture $W(\mathrm{~kg} / \mathrm{s})$ multiplied by the combustion efficiency factor $\eta$, which accounts for combustion completeness (fraction of the released gas, which is combusted). Then the resulting equation of the heat flux received by the damage receptor is given by

$$
I(r)=F \tau \frac{H W \eta}{4 \pi r^{2}}
$$

According to [6], the radiated fraction of heat $F$ in general depends on several factors: efficiency of combustion, soot formation and heat losses and for jet flames is a function of the fuel and orifice diameters, usually with values between 0.15 and 0.3 .

The atmospheric transmissivity coefficient $\tau$ can be calculated according to empirical Wayne correlation [7], which is valid for infrared radiation over the absorbing distances of 10 to $1000 \mathrm{~m}$ :

$$
\begin{aligned}
\tau= & 1.006-0.01171 \cdot \log \left(X_{\mathrm{H}_{2} \mathrm{O}}\right)-0.02368 \cdot \log ^{2}\left(X_{\mathrm{H}_{2} \mathrm{O}}\right)- \\
& -0.03188 \cdot \log \left(X_{\mathrm{CO}_{2}}\right)+0.001164 \cdot \log ^{2}\left(X_{\mathrm{CO}_{2}}\right)
\end{aligned}
$$

where $X_{\mathrm{H}_{2} \mathrm{O}}=R_{H} r S_{m m}\left(\frac{288.651}{T}\right)$ and $X_{\mathrm{CO}_{2}}=r \frac{273}{T}, R_{H}$ is the fractional relative humidity, $S_{m m}$ is the saturated vapour pressure $(\mathrm{mm} \mathrm{Hg})$ of water at atmospheric temperature $T(\mathrm{~K})$.

The gas release rate $W$ varies in time. Beginning from its peak value it decreases and just after few seconds a fraction of the peak value is left, which is further decreasing.

Initial (peak) gas flow value can be estimated using Crane Co. [8] equation:

$$
W=C_{d} \frac{\pi d^{2}}{4} p \frac{\varphi}{a_{0}}
$$

here $\mathrm{C}_{\mathrm{d}}$ is the gas discharge coefficient, $d$ - the diameter of the opening, in the case of guillotine rupture equal to the diameter of the pipe (m), $p$ - the pressure difference $(\mathrm{Pa}), \varphi=\gamma\left(\frac{2}{\gamma+1}\right)^{\frac{\gamma+1}{2(\gamma-1)}}, \gamma-$ the specific heat ratio, $a_{0}-$ the sound speed in the gas $(\mathrm{m} / \mathrm{s})$.

The varying gas flow will cause the flame size and radiation intensity to vary accordingly. The peak value of the thermal radiation intensity is not known beforehand and depends on the time interval between the rupture and the ignition. In the presented model varying gas flow $W$ is modelled by constant "effective" gas flow $W_{\text {eff }}=2 \lambda W$, where $\lambda$ is the flow reduction coefficient and 2 is required to account for gas flow from both ends of the ruptured pipe. Values of $\lambda$ used in the analogous studies are, e.g., 0.25 [9] and 0.33 [5]. More conservative value of 0.5 has been selected in this study. 


\subsection{Assessment of radiation impact}

Usually, the damage from the thermal radiation is estimated using model, which relates the received heat flux, the exposure time and possible damage (Table 2).

Table 2: $\quad$ Time needed to cause various damage to humans.

\begin{tabular}{|c|c|c|c|c|}
\hline $\begin{array}{c}\text { Heat } \\
\text { flux, } I \\
\left(\mathrm{~W} / \mathrm{m}^{2}\right)\end{array}$ & $\begin{array}{c}\text { Time (s) to blister } \\
\text { threshold, } \\
t^{*} I^{1.33}=210 \text { and } \\
t^{*} I^{1.33}=700[1]\end{array}$ & $\begin{array}{c}\text { Time (s) to } 1 \% \\
\text { mortality, } \\
t^{*} I^{1.33}=1060[1]\end{array}$ & $\begin{array}{c}\text { Time (s) to 50\% } \\
\text { mortality, } \\
t^{*} I^{1.33}=2300[1]\end{array}$ & $\begin{array}{c}\text { Time (s) to } \\
100 \% \\
\text { mortality, } \\
t^{*} I^{1.33}=3500[1]\end{array}$ \\
\hline 3180 & $45.1-150.3$ & 227.6 & 493.7 & 751.4 \\
\hline 7870 & $13.5-45.0$ & 68.2 & 147.9 & 225.1 \\
\hline 10760 & $8.9-29.7$ & 45.0 & 97.6 & 148.5 \\
\hline 19260 & $4.1-13.7$ & 20.7 & 45.0 & 68.5 \\
\hline 26410 & $2.7-9.0$ & 13.6 & 29.6 & 45.0 \\
\hline
\end{tabular}

If one chose a time period during which any person receiving flame radiation would be able to find a shelter, it is possible to directly relate intensity of radiation and worst possible impact on the health. In the [5], this time period is selected to be equal to $30 \mathrm{~s}$, on the assumption that affected person would be able to travel a distance of about $60 \mathrm{~m}$ in this period. In this work a distance of $100 \mathrm{~m}$ and corresponding time period of $45 \mathrm{~s}$ is selected conservatively. Table 3 shows intervals of approximate thermal radiation intensity relating to different damage levels in this case.

Table 3: Heat flux intervals relating to selected damage to humans.

\begin{tabular}{|c|c|c|}
\hline Heat flux $\left(\mathrm{W} / \mathrm{m}^{2}\right)$ & Damage & Interval label \\
\hline $26410-\ldots$ & $100 \%$ mortality & $\mathrm{A}$ \\
\hline $19260-26410$ & $50-100 \%$ mortality & $\mathrm{B}$ \\
\hline $10760-19260$ & $0-50 \%$ mortality & $\mathrm{C}$ \\
\hline $3180-10760$ & Blisters & $\mathrm{D}$ \\
\hline $0-3180$ & No damage & $\mathrm{E}$ \\
\hline
\end{tabular}

For buildings, analogous models exist, which relate radiation intensity and time needed for the building ignition. However, one important difference compared to human damage models is present in building damage models - heat flux threshold below which no ignition would occur [6]. Furthermore, buildings cannot run for shelter, therefore no time limit can be assumed for the damage but 
the time to put out the fire. Using Bilo and Kinsman model of the time to piloted ignition of the wooden structure [5] and conservatively assuming that time needed to put out the fire is 24 hours, the heat flux value of $14760 \mathrm{~W} / \mathrm{m}^{2}$ is obtained (threshold value is $14700 \mathrm{~W} / \mathrm{m}^{2}$ ).

\subsection{Estimation of hypothetical explosion strength}

The strength of a hypothetical explosion can be estimated using standard TNT equivalence method. In this method, semi-empirical approximations of a relation between overpressure $P$ and scaled distance $Z$ are employed. In this work, an expression of the peak overpressure introduced by Mills [10] is used:

$$
P=\frac{1772}{Z^{3}}-\frac{114}{Z^{2}}+\frac{108}{Z}
$$

The formula for scaled distance is

$$
Z=\frac{r}{\sqrt[3]{\alpha \frac{m H}{H_{T N T}}}}
$$

where $r$ is the real distance, $\mathrm{m}, \alpha$ is the energy equivalence coefficient, $m$ is the mass of the combustible gas in the mixture, $\mathrm{kg}$, and $H_{T N T}$ is the TNT explosive energy, 4,68 MJ/kg.

The energy equivalence coefficient $\alpha$ shows the fraction of the explosion energy which becomes the energy of a pressure wave. Experiments show that its values for the explosions of gas mixture are less than $10 \%$ [11],[12], and in the majority cases it is lower than 3\% [13-16].

Obtained shock wave overpressure can be approximately related to the effects on structures (Table 4).

Table 4: $\quad$ Overpressure intervals relating to expected damage [17].

\begin{tabular}{|c|c|}
\hline Overpressure $(\mathrm{Pa})$ & Expected damage \\
\hline $1000-1500$ & Window glass cracks \\
\hline $3500-7600$ & Minor damage in some buildings \\
\hline $7600-12400$ & Metal panels deformed \\
\hline $12400-20000$ & Concrete walls damage \\
\hline$>35000$ & Wooden construction buildings demolition \\
\hline $27500-48000$ & Major damage on steel construction objects \\
\hline $40000-60000$ & Heavy damage on reinforced concrete buildings \\
\hline $70000-80000$ & Probable demolition of most buildings \\
\hline
\end{tabular}

\section{Application of the method}

In this section an example of the method application is presented. The object of the application in this example is a part of a natural gas pipeline, considered to 
be one pipe of $10 \mathrm{~km}$ length. Its inner diameter is $0.18 \mathrm{~m}$, pressure $0.6 \mathrm{MPa}$. The gas inside the pipe is methane ( $100 \%$ concentration assumed).

Using the expressions of heat flux and effective gas release rate we obtain damage intervals and heat flux dependency on the distance from the rupture place on this pipe (Figure 2). (50\% air humidity, $273 \mathrm{~K}$ temperature, 0.3 fraction of heat radiated and 0.62 gas discharge coefficient were assumed).

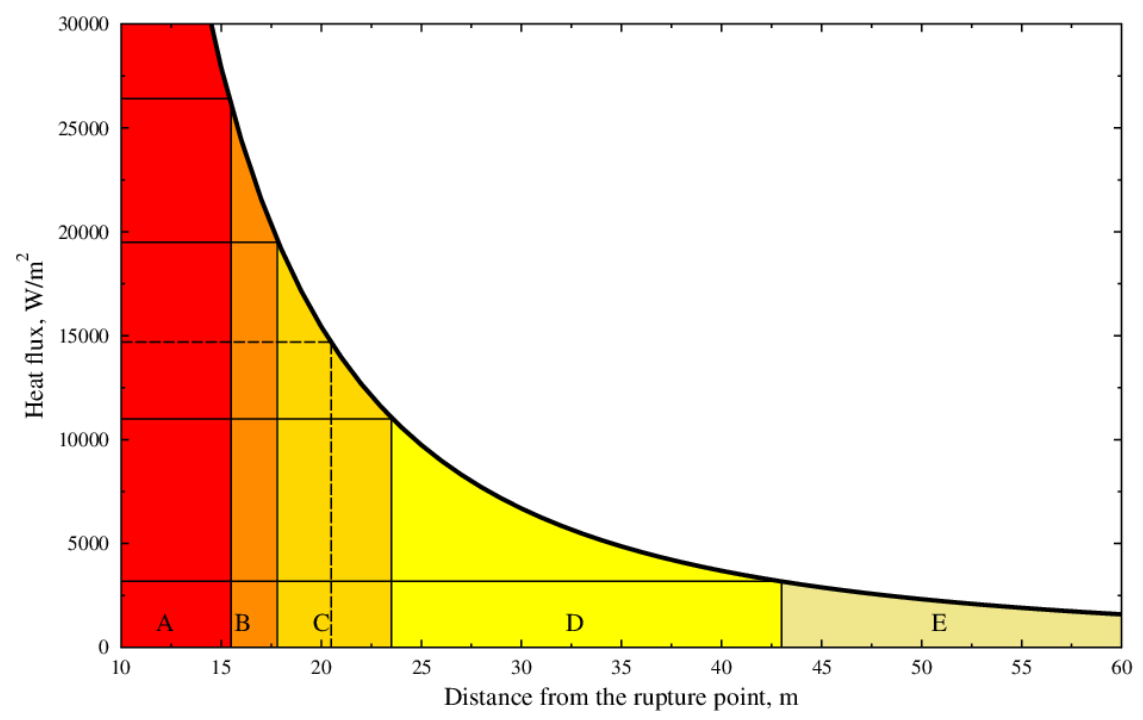

Figure 2: Damage intervals obtained for the example natural gas pipe. Dashed line in the middle of $\mathrm{C}$ interval corresponds to the obtained maximum distance for the building damage.

In order to estimate strength of a hypothetical explosion, the mass of the combustible mixture and its contents must be known. The most conservative approach would be to assume that the whole contents of the affected pipeline section were to form combustible mixture, at the stoichiometric concentration. However, if the leaked gas was buoyant (e.g., methane) and large section of the pipeline was affected, results obtained with this assumption would be extremely unrealistic and useful only as a theoretical worst-case maximum overpressure. It is used in this example only as a simplest approach to the problem. Using this assumption, we obtain the mass of the pipe contents from the ideal gas equation:

$$
m=\frac{\pi \mu d^{2} L p}{4 R T}
$$

From this mass we obtain dependence of the overpressure caused by an explosion on the distance from the detonation centre (Figure 3:) using eqn. (6) and (7). 


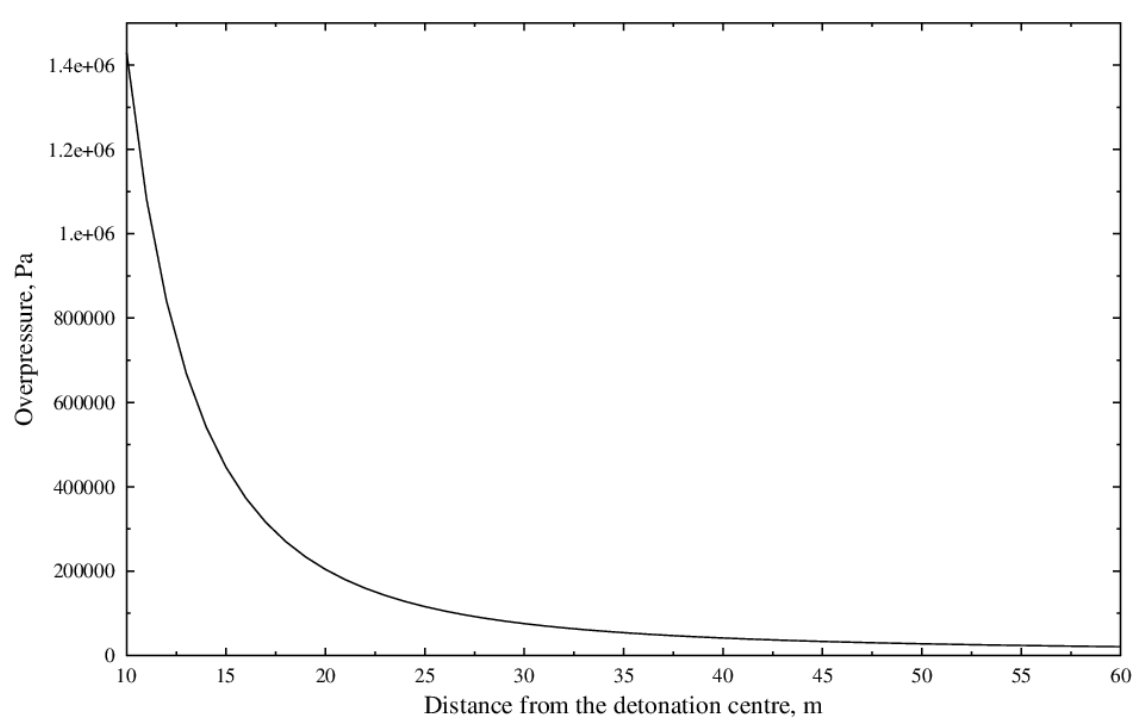

Figure 3: Shock wave overpressure at different distance from the explosion epicentre.

As demonstrated by the example, it is possible to apply the developed method in the assessment of the reliability and risk of gas supply systems and the consequence assessment of gas pipeline ruptures, which are important for the justification of site selection for new potentially dangerous objects, such as, e.g., nuclear power plants.

There are a number of uncertain parameters in the developed method and in this paper conservative estimations of their values were used. A further study on the impact of these parameters (uncertainty analysis) is being performed and will be published in the future.

\section{Conclusions}

Developed method for hazard evaluation of natural gas pipelines allows easy and conservative estimate of probability of the gas explosion and the assessment of the possible damage in the case of pipeline rupture and subsequent sustained jet fire. Also estimation of overpressures caused by a shock wave from the hypothetical worst-case detonation is made possible.

\section{Acknowledgement}

This research was funded by a grant (No. ATE-10/2010) from the Research Council of Lithuania. 


\section{References}

[1] Helseth, A., Holen, A. T. Reliability modelling of gas and electric power distribution systems; similarities and differences. Proceedings of 9th International Conference on Probabilistic Methods Applied to Power Systems. Stockholm: KTH, June 11-15, 2006.

[2] EGIG 2007. 7th EGIG-report 1970-2007 Gas Pipeline Incidents, 7th report of the European Gas Pipeline Incident Data Group, Doc. No. EGIG 08. TVB.0502, 2007.

[3] Arunakumar, G. UKOPA Pipeline Fault Database. Pipeline Product Locc Incidents (1962-2008). 6th Report of the UKOPA Fault Database Management Group. 2009, December.

[4] Iešmantas T., Alzbutas R. Age-dependent probabilistic analysis of failures in gas pipeline networks // Proc. of $8^{\text {th }}$ Annual Conference of Young Scientists on Energy Issues. CYSENI 2011, 26-27 May 2011, Lithuania. ISSN 1822-7554. p. 1-9.

[5] Stephens, M. J., A model for sizing high consequence areas associated with natural gas pipelines, Topical report, C-FER Technologies, Canada, 2000.

[6] Mannan, S., Lees' Loss Prevention in the Process Industries, ButterworthHeinemann, 2004.

[7] Wayne, F. D., An economical formula for calculating atmospheric infrared transmissivities. Journal of Loss Prevention in the Process Industries, 4(2), pp. 86-92, 1991.

[8] Crane Technical Paper No. 410 (TP-410), Flow of fluids through valves, fittings, and pipe, Crane Company, 2009.

[9] HSE Contract research report $\mathrm{n}^{\circ}$ 82/1994, Risk from hazardous pipelines in the United Kingdom, HSE Books, 1995.

[10] Mills, C.A., The design of concrete structure to resist explosions and weapon effects, Proc. of the $1^{\text {st }}$ Intl. Conf. On Concrete For Hazard Protections, Edinburgh, UK, pp. 61-73, 1987.

[11] Gugan, K., Unconfined vapor cloud explosions, IChemE, London, 1978.

[12] Pritchard, D. K., A review of methods for predicting blast damage from vapor cloud explosions. Journal of Loss Prevention in the Process Industries, 2(4), pp. 187-193, 1989.

[13] Brasie, W. C., Simpson, D. W., Guidelines for estimating damage explosion. Proc. 63 ${ }^{\text {rd }}$ Nat. AIChE Meeting, AIChE: New York. 1968.

[14] Davenport, J. A., A study of vapor cloud incidents, AIChE Loss prevention symposium, Houston, Texas, 1977.

[15] Davenport, J. A., A study of vapor cloud incidents - an update, 4th Int. Symp. Loss prevention and safety promotion in the process industrines, Harrogate, IChemE Symp. Series No. 80. 1983.

[16] Kletz, T. A., Unconfined vapor cloud explosions - an attempt to quantify some of the factors involved, AIChE Loss prevention symposium, Houston, Texas, 1977.

[17] Jeremic, R., Bajic, Z., An approach to determining the TNT equivalent of high explosives, Scientific-Technical Review, 56, pp. 58-62, 2006. 